\title{
Expression of Inflammation-Related Genes in Gluteal and Abdominal Subcutaneous Adipose Tissue During Weight-Reducing Dietary Intervention in Obese Women
}

\author{
L. MALIŠOVÁ ${ }^{1,2}$, L. ROSSMEISLOVÁ ${ }^{1,2}$, Z. KOVÁČOVÁA ${ }^{1,2}$, J. KRAČMEROVÁA $^{1,2}$, \\ M. TENCEROVÁ ${ }^{1,2}$, D. LANGIN ${ }^{2,3,4,5}$, M. ŠIKLOVÁ-VÍTKOVÁ ${ }^{1,2}$, V. ŚTICH $^{1,2}$ \\ ${ }^{1}$ Department of Sport Medicine, Third Faculty of Medicine, Charles University in Prague, Prague, \\ Czech Republic, ${ }^{2}$ Franco-Czech Laboratory for Clinical Research on Obesity, Third Faculty \\ of Medicine, Charles University, Prague, Czech Republic and INSERM, Toulouse, France, \\ ${ }^{3}$ INSERM, UMR1048, Obesity Research Laboratory, Team 4, I2MC, Institute of Metabolic and \\ Cardiovascular Diseases, Toulouse, France, ${ }^{4}$ University of Toulouse, UMR1048, Paul Sabatier \\ University, Toulouse, France, ${ }^{5} \mathrm{CHU}$ de Toulouse, Laboratory of Clinical Biochemistry, Toulouse, \\ France
}

Received February 28, 2013

Accepted August 1, 2013

On-line November 1, 2013

\section{Summary}

Accumulation of adipose tissue in lower body lowers risk of cardiovascular and metabolic disorders. The molecular basis of this protective effect of gluteofemoral depot is not clear. The aim of this study was to compare the profile of expression of inflammation-related genes in subcutaneous gluteal (sGAT) and abdominal (SAAT) adipose tissue at baseline and in response to multiphase weight-reducing dietary intervention (DI). 14 premenopausal healthy obese women underwent a 6 months' DI consisting of 1 month very-low-calorie-diet (VLCD), subsequent 2 months' low-calorie-diet and 3 months' weight maintenance diet (WM). Paired samples of SGAT and SAAT were obtained before and at the end of VLCD and WM periods. mRNA expression of 17 genes (macrophage markers, cytokines) was measured using RT-qPCR on chip-platform. At baseline, there were no differences in gene expression of macrophage markers and cytokines between sGAT and SAAT. The dynamic changes induced by DI were similar in both depots for all genes except for three cytokines (IL6, IL10, CCL2) that differed in their response during weight maintenance phase. The results show that, in obese women, there are no major differences between sGAT and SAAT in expression of inflammation-related genes at baseline conditions and in response to the weight-reducing DI.

\section{Key words}

Body fat distribution - Hypocaloric diet - Macrophages • Cytokines

\section{Corresponding author}

Vladimír Štich, Charles University in Prague, Third Faculty of Medicine, Department of Sport Medicine, Ruská 87, 10000 Prague 10, Czech Republic. E-mail: Vladimir.Stich@If3.cuni.cz

\section{Introduction}

Obesity is associated with higher risk of metabolic and cardiovascular diseases. In addition to body mass index (BMI), body fat distribution plays a major role in the development of the above mentioned diseases. While upper body fat accumulation is associated with increased obesity-related health risk, the lower body fat accumulation was shown to be linked with the reduction of metabolic (Snijder et al. 2004), cardiovascular risk (Canoy et al. 2007, Faloia et al. 2009, Seidell et al. 2001) and with lower morbidity and mortality (Folsom et al. 1993, Pischon et al. 2008). The increased amount of lower body fat - expressed as hip circumference - was associated with lower triacylglycerol and higher HDL cholesterol levels (Ruige and Van Gaal 2009). 
Possible mechanisms that may contribute to the subcutaneous gluteal adipose tissue (sGAT) protective role have not been fully elucidated. Different uptake and release of fatty acids in the subcutaneous abdominal (sAAT) when compared to sGAT have been suggested as a candidate underlying cause (Berman et al. 1998, Berman et al. 2004). In several studies, the activity of lipoprotein lipase (LPL) was found to be higher (Arner et al. 1991, Ferrara et al. 2002) in sGAT in obese women. This might suggest a higher capacity of sGAT for lipid accumulation.

In addition to alteration of adipose tissue (AT) fatty acid handling, the obesity-related metabolic disturbances are linked with pro-inflammatory state of AT characterized by enhanced recruitment of macrophages in AT and modified AT secretion of cytokines (Klimcakova et al. 2011, O'Hara et al. 2009, Suganami and Ogawa 2010, Trayhurn and Wood 2004). Thus, it may be hypothesized that differences in the inflammation-related characteristics underlie the differences in metabolic role of sGAT when compared with sAAT. Few studies paid attention to this topic. Recently, Evans et al. (2011) showed that sGAT had, contrary to the expectation, greater mRNA expression of a set of pro-inflammatory genes than SAAT.

Thus the first aim of our study was to compare, in obese women, expression of wider range of cytokines and macrophage markers in sGAT vs. sAAT (selected according to our previous studies of Capel et al. 2009, Klimcakova et al. 2011, Siklova-Vitkova et al. 2012) and their association with indices of metabolic syndrome. Our second aim was to explore the regulation of expression of the above mentioned genes in a dynamic condition that was realized by a dietary intervention (DI) using hypocaloric diet. It was shown previously that hypocaloric diet-induced changes in adipocyte lipolysis (Mauriege et al. 1999) or in adipocyte size (Bjorntorp et al. 1975) were less pronounced in SGAT when compared with sAAT. We hypothesized that this impaired responsiveness, or "inflexibility", of sGAT might also appear in respect to the diet-induced modulation of gene expression of immunityrelated genes. Thus, we measured mRNA expression of the respective genes in the paired samples of sGAT and sAAT obtained in obese women before and during multiple phases of a 6 months' hypocaloric DI.

\section{Materials and Methods}

\section{Subjects}

14 premenopausal obese women (BMI 34.2 \pm 2.6 $\mathrm{kg} / \mathrm{m}^{2}$, range 27-49 years) without medication and diseases except for obesity participated in this study. Their body weight had been stable for 3 months prior to the examination. The informed consent was obtained from each patient before the study. The study was performed according to the Declaration of Helsinki protocols and was approved by Ethical Committee of the Third Faculty of Medicine, Charles University in Prague.

\section{Dietary intervention and clinical investigation}

The entire DI lasted 6 months. During the first dietary period, obese subjects received a very low calorie diet (VLCD) of $800 \mathrm{kcal} /$ day (liquid formula diet, Redita, Promil, Czech Republic) for 1 month. The subsequent period consisted of a 2 months' low-calorie diet (LCD) followed by 3 months' weight maintenance (WM) diet. LCD was designed to provide $600 \mathrm{kcal} /$ day less than the individually estimated energy requirement based on an initial resting metabolic rate multiplied by 1.3 , the coefficient of correction for physical activity level. Patients consulted a dietician once a week during the first 3 months of the program and once a month during subsequent phase. They provided a written 3 days' dietary record at each dietary consultation.

Complete clinical investigation including anthropometric measurements, blood sampling and AT biopsies was performed in the morning in the fasting state before the beginning of the diet and at the end of VLCD and WM periods.

The whole body composition was evaluated by multi-frequency bioimpedance (Bodystat, Quad scan 4000, Isle of Man, UK). The blood was collected and centrifuged at $1300 \mathrm{RPM}, 4{ }^{\circ} \mathrm{C}$, separated plasma was stored at $-80^{\circ} \mathrm{C}$ until analysis. The paired samples of subcutaneous AT were obtained from the subcutaneous abdominal (10 cm lateral to the umbilicus) and gluteal (right upper quadrant) region using needle biopsy under local anesthesia ( $1 \%$ Xylocaine). AT samples were obtained from superficial sAAT, as we verified on several occasions using ultrasonography. AT was washed in physiological saline, aliquoted, snap-frozen in liquid nitrogen and stored at $-80{ }^{\circ} \mathrm{C}$ until processing.

\section{Laboratory measurements}

Plasma glucose was determined using the glucose-oxidase technique (Beckman Instruments, Fullerton, CA). Plasma insulin was measured using an Immunotech Insulin Irma kit (Immunotech, Prague, Czech Republic). Homeostasis model assessment of the insulin resistance index (HOMA-IR) was calculated as follows: ((fasting insulin in $\mathrm{mU} / \mathrm{l}) \mathrm{x}$ (fasting glucose in 
Table 1. Clinical characteristics of subjects and plasma levels of cytokines before dietary intervention (basal) and at the end of VLCD and weight maintenance (WM) phase of the dietary intervention.

\begin{tabular}{|c|c|c|c|}
\hline & Basal & VLCD & $\mathbf{W M}$ \\
\hline Age (year) & $27-49$ & & \\
\hline$B M I\left(\mathrm{~kg} / \mathrm{m}^{2}\right)$ & $34.2 \pm 0.2$ & $31.5 \pm 0.2 * * *$ & $30.4 \pm 0.2 \dagger \dagger \dagger$ \\
\hline Weight (kg) & $93.5 \pm 0.6$ & $86.0 \pm 0.6^{* * *}$ & $83.1 \pm 0.7 \dagger \dagger \dagger$ \\
\hline Waist circumference $(\mathrm{cm})$ & $102.3 \pm 0.4$ & $95.4 \pm 0.6^{* * *}$ & $93.6 \pm 0.6 \dagger \dagger \dagger$ \\
\hline Hip circumference $(\mathrm{cm})$ & $119.1 \pm 0.5$ & $114.1 \pm 0.5^{* * *}$ & $112.1 \pm 0.5 \dagger \dagger \dagger$ \\
\hline Waist to hip ratio $(\mathrm{cm})$ & $0.861 \pm 0.0$ & $0.838 \pm 0.0^{*}$ & $0.836 \pm 0.0 \dagger \dagger$ \\
\hline Fat mass $(\%)$ & $41.9 \pm 0.3$ & $39.4 \pm 0.4 * * *$ & $37.2 \pm 0.4 \dagger \dagger \dagger$ \\
\hline$F F M(\%)$ & $58.1 \pm 0.3$ & $60.1 \pm 0.4^{*}$ & $63.0 \pm 0.5 \dagger \dagger$ \\
\hline Glucose (mmol/l) & $4.9 \pm 0.4$ & $4.6 \pm 0.0^{*}$ & $4.7 \pm 0.0$ \\
\hline Insulin (mIU/l) & $11.7 \pm 0.8$ & $8.0 \pm 0.3^{*}$ & $9.0 \pm 0.4 \dagger$ \\
\hline FFA $(\mu \mathrm{mol} / \mathrm{l})$ & $842 \pm 60.1$ & $1190 \pm 28.2^{*}$ & $676 \pm 13.5 \dagger$ \\
\hline Triglycerides (mmol/l) & $1.6 \pm 0.0$ & $1.2 \pm 0.0$ & $1.5 \pm 0.0$ \\
\hline HDL cholesterol (mmol/l) & $2.0 \pm 0.0$ & $1.2 \pm 0.0$ & $1.6 \pm 0.0$ \\
\hline Total cholesterol $(\mathrm{mmol} / \mathrm{l})$ & $5.2 \pm 0.0$ & $4.3 \pm 0.0 * * *$ & $5.2 \pm 0.0$ \\
\hline$H O M A-I R$ & $2.6 \pm 0.1$ & $1.7 \pm 0.1^{*}$ & $1.9 \pm 0.1 \dagger \dagger$ \\
\hline$h s-C R P(m g / l)$ & $5.8 \pm 0.4$ & $4.2 \pm 0.3$ & $4.0 \pm 0.3 \dagger$ \\
\hline IL10 (pg/ml) & $1.4 \pm 0.4$ & $1.5 \pm 0.6$ & $1.5 \pm 0.6$ \\
\hline$I L 6(\mathrm{pg} / \mathrm{ml})$ & $3.7 \pm 0.1$ & $3.1 \pm 0.1$ & $2.6 \pm 0.1$ \\
\hline$T N F(p g / m l)$ & $2.0 \pm 0.1$ & $2.3 \pm 0.1 * *$ & $2.0 \pm 0.1$ \\
\hline CCL2 $(\mathrm{pg} / \mathrm{ml})$ & $104.3 \pm 4.7$ & $103.1 \pm 3.2$ & $86.4 \pm 2.7 \dagger$ \\
\hline
\end{tabular}

Values are means $\pm \mathrm{SEM}, \mathrm{n}=14$. Significance was set as follows: VLCD vs. basal: $* \mathrm{p}<0.05, * * \mathrm{p}<0.01, * * * \mathrm{p}<0.001$, WM phase vs. basal: $+p<0.05$, $+\dagger p<0.01$, $++\dagger p<0.001$. BMI, body mass index; CCL2, chemokine ( $C-C$ motif) ligand 2; FFM, fat-free mass; HOMAIR, homeostasis model assessment of the insulin resistance index; hs-CRP, high-sensitivity C-reactive protein; IL6, interleukin 6; IL10, interleukin 10; FFA, free fatty acids; TNF, tumor necrosis factor

mmol/1) / 22.5). Plasma levels of other relevant substances were determined using standard clinical biochemistry methods. Plasma levels of cytokines were determined using multiplex human cytokines Milliplex panels (Millipore-Merck, Bedford, MA, USA).

\section{Gene expression analysis}

Total RNA was isolated from 100-300 mg aliquots of AT using RNeasy Lipid Tissue RNA Mini kit (Qiagen, Hilden, Germany). RNA concentration was measured by Nanodrop1000 (Thermo Fisher Scientific, Wilmington, Delaware, USA). Genomic DNA was removed by DNAse I treatment (Invitrogen, Carlsbad, CA, USA). cDNA was obtained by reverse transcription (High Capacity cDNA Reverse Transcription Kit, Applied Biosystem, Carlsbad, CA, USA) using 200 ng of total RNA. $1 \mathrm{ng}$ of cDNA was then preamplified to improve detection of target genes during subsequent Real Time qPCR (16 cycles, TaqMan Pre Amp Master Mix Kit, Applied Biosystem). For the preamplification, $20 \mathrm{x}$
TaqMan gene expression assays of all target genes were pooled together and diluted with $1 \mathrm{x}$ TE buffer to the final concentration $0.2 \mathrm{x}$ (each probe). The RT-qPCR was performed on Biomark Real Time qPCR system and 96x96 chip (Fluidigm, USA) in triplicates. This part of analysis was carried out as a paid service by Biotechnology Institute, AS CR.

Expression of 17 genes grouped according to their origin or function was measured: cytokines (IL6, TNF, CCL2, CXCL1, IL10, TGF 1 1, IL10RA) and cytokine receptor (CCR2), macrophage markers (SPP1, CD68, MSR1, PLA2G7, ACP5, FCGBP, CD14, TLR4, TLR2). Macrophage markers were selected according to the work of Capel et al. (2009) and Klimcakova et al. (2011) and cytokines produced predominantly by cells of stromavascular fraction were chosen according to study of Siklova-Vitkova et al. (2012) so that comparisons of outcomes between this and our previous studies were enabled. Expression data were normalized to expression of reference gene, PPIA, and delta $\mathrm{Ct}$ was 

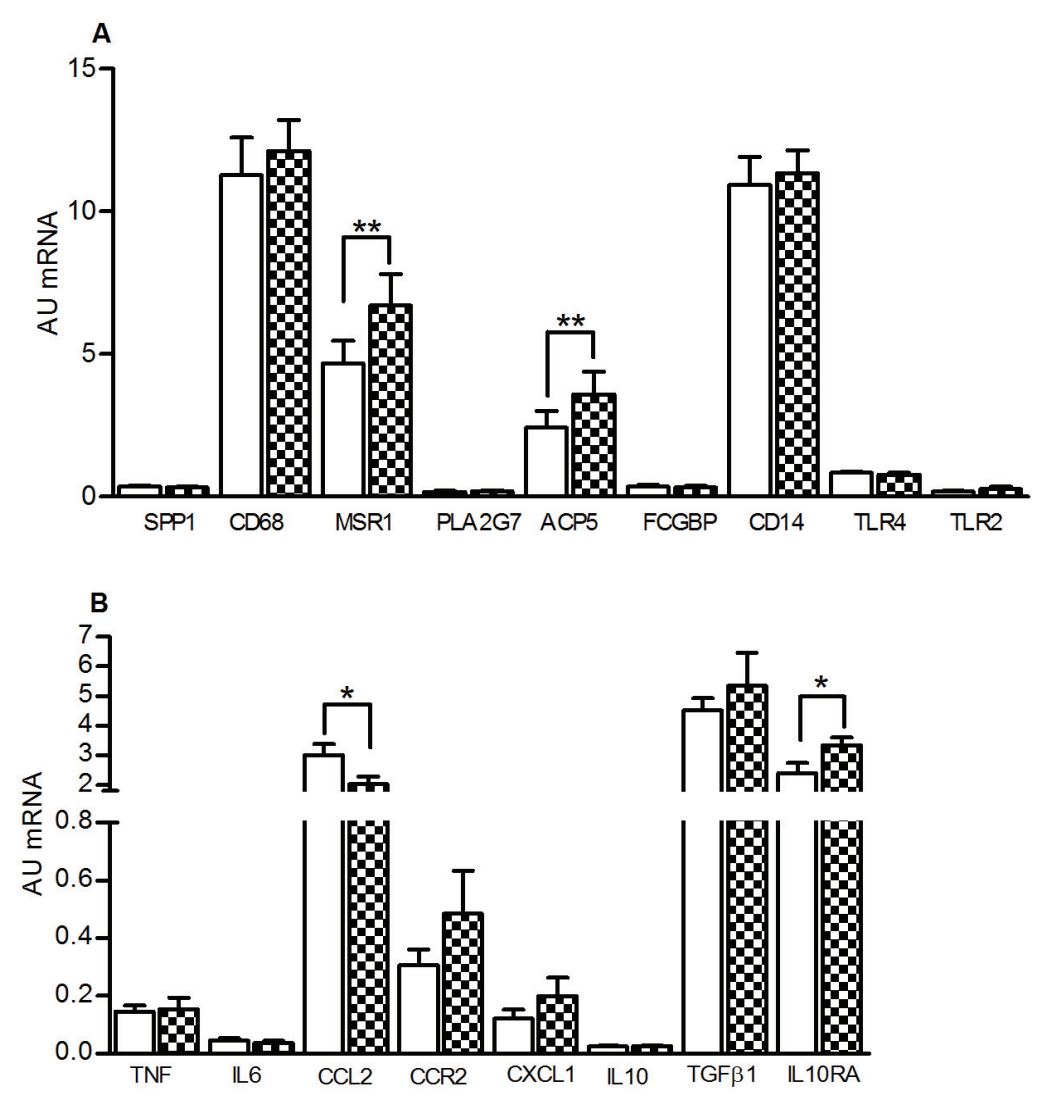

Fig. 1. Adipose tissue gene expression in basal state, before the diet. A: macrophage markers, B: cytokines. Subcutaneous abdominal adipose tissue (open columns), subcutaneous gluteal adipose tissue (cross-hatched columns). Each column represents mean of gene expression levels calculated as delta $\mathrm{Ct}$ (normalized to PPIA). $* \mathrm{p}<0.05, * * \mathrm{p}<0.01$ log-transformed for statistical analysis.

\section{Statistical analysis}

The data from RT-qPCR were analyzed with Genex software (MultiD Analysis AB, Sweden) and SPSS version 13.0 (SPSS Inc., Chicago, IL, USA). For all the analyses the data were log-transformed. One way ANOVA was used for comparison of gene expression separately in each depot, the effect of sAAT vs. sGAT on the diet-induced changes was estimated by two way ANOVA with repetitive measures and Tukey's posthoc analysis. The level of significance was set at $\mathrm{p}<0.05$. Clinical and anthropometrical data were analyzed with GraphPad Prism 5.0. (La Jolla, CA, USA). Correlations were performed using Pearson's parametric test.

\section{Results}

Effect of dietary intervention on anthropometrical and plasma variables

The clinical data of the entire group of subjects at baseline and during the DI are presented in Table 1. When compared to baseline, the subjects' body weight decreased by $8.0 \%$ after the VLCD and decreased further during subsequent period so that the weight loss at the end of WM represented $11.1 \%$ of the original weight.
BMI, fat mass, waist and hip circumference showed a similar pattern. The relative decrease of waist circumference was greater than that of hip circumference at the end of VLCD as well as at the end of the entire DI (VLCD: waist: $-6.8 \pm 0.3 \%$, hip: $-4.2 \pm 0.3 \%, \mathrm{P}<0.05$, the end of DI: waist: $-8.6 \pm 0.2 \%$, hip: $-5.9 \pm 0.3 \%, \mathrm{P}<0.01)$. Plasma levels of insulin were lower at the end of VLCD when compared to baseline condition and remained lower at the end of WM. Glycemia and total cholesterol decreased after VLCD and returned to the baseline levels at WM. Free fatty acid levels were increased after VLCD and decreased below the baseline values at the end of the WM. Insulin resistance assessed by HOMA-IR decreased during VLCD and remained reduced at the end of WM phase. The changes of plasma levels of cytokines IL10, IL6, TNF, CCL2 were in line with our previous study (Siklova-Vitkova et al. 2012).

Comparison of gene expression in gluteal and abdominal subcutaneous AT in obese women at pre-diet condition (Fig. 1)

To compare gene expression profile in sAAT and sGAT, we measured mRNA expression of 17 genes divided into 2 functional groups: macrophage markers (9 genes), cytokines ( 8 genes), and reference gene PPIA. The expression of macrophage markers was similar in 


\section{Macrophage markers}

A Expression in abdominal adipose tissue

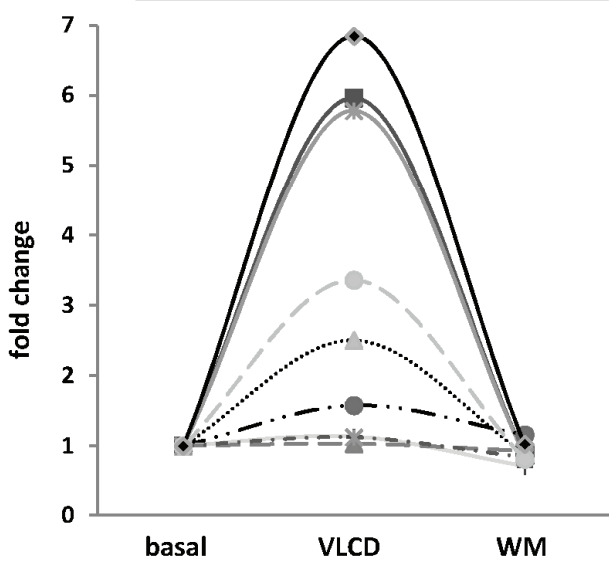

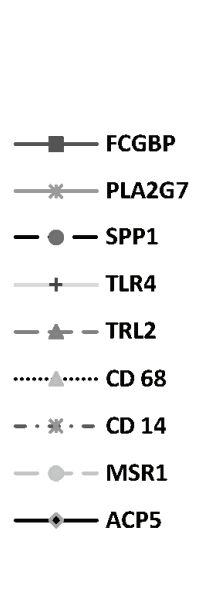

Cytokines
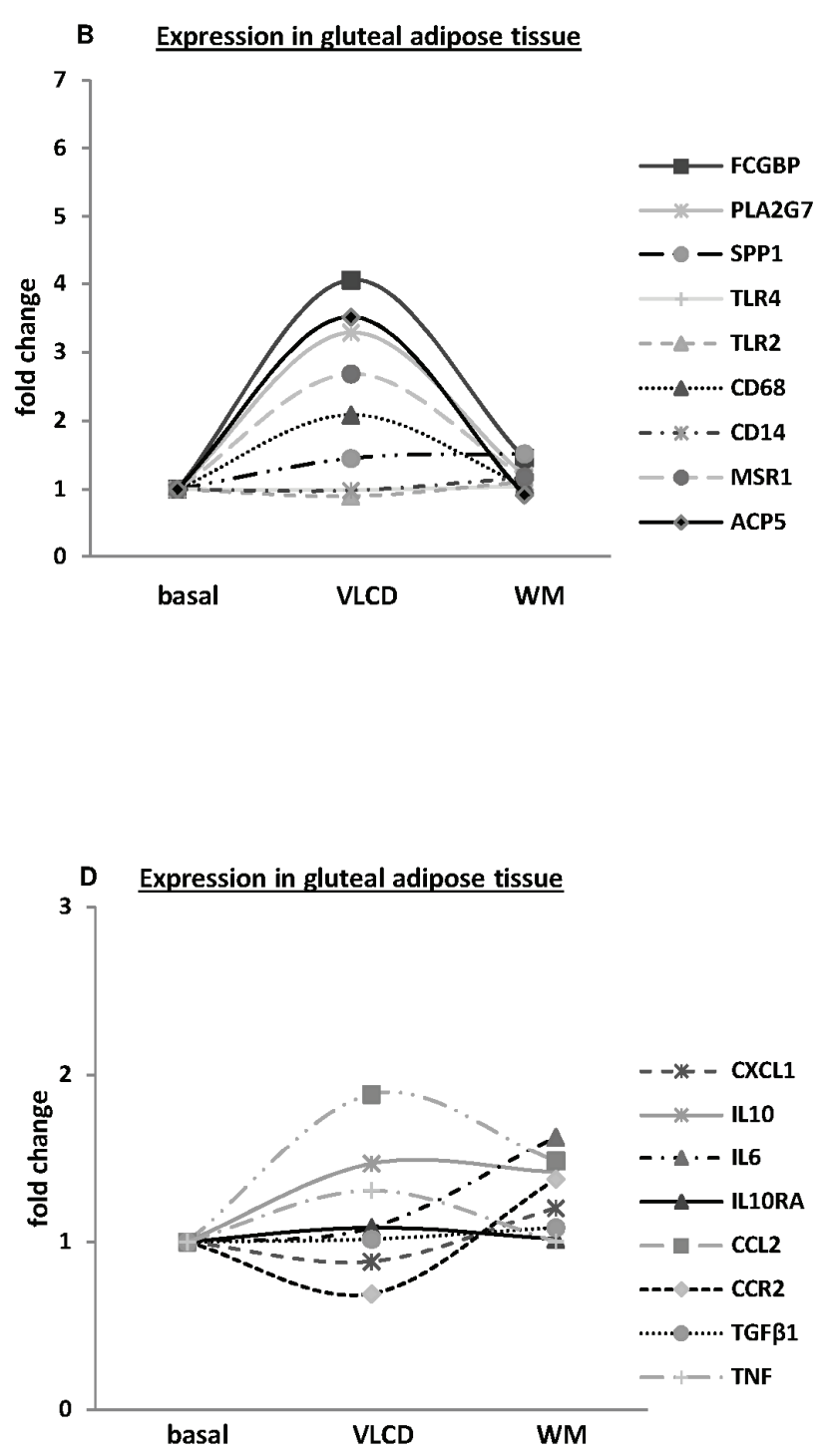
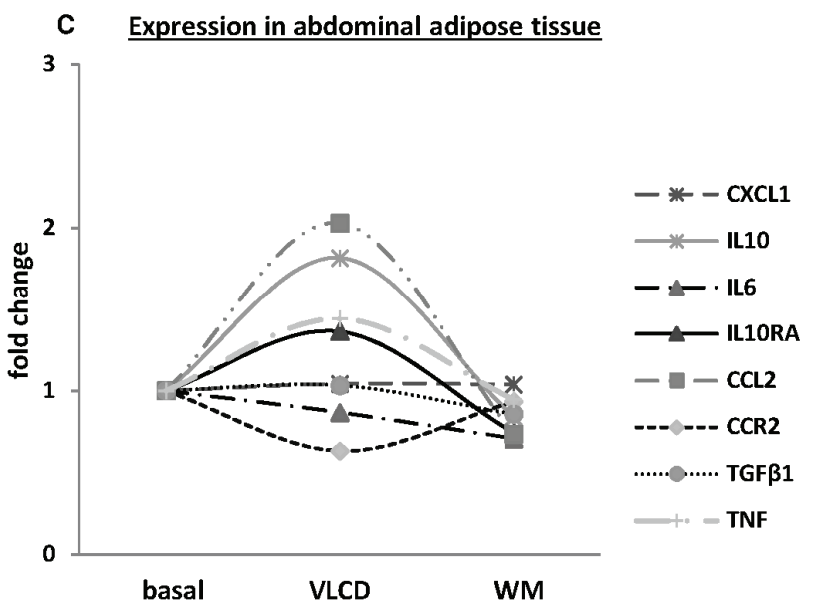

Fig. 2. Profile of gene expression in subcutaneous abdominal (SAAT) and gluteal (sGAT) adipose tissue during the two phases (VLCD and WM) of dietary intervention. A and B: Expression of macrophage markers in SAAT (A) and SGAT (B). C and D: Expression of cytokines in SAAT (C) and sGAT (D). The data are presented as fold change in respect to the pre-diet (basal) levels. Data are presented as means \pm SEM.

both depots except for two genes, ACP5 and MSR1 that had higher expression in sGAT compared to sAAT (Fig. 1A). There were no depot-related differences in the expression of all measured cytokines (TNF, IL6, CCR2, CXCL1, IL10, TGF $\beta 1$ ) with exception of IL10RA (higher in sGAT) and CCL2 (lower in sGAT) (Fig. 1B).

Effect of dietary intervention on gene expression in gluteal and abdominal subcutaneous AT (Fig. 2, Table 2)

The evolution of the mRNA expression for individual genes during DI is shown in Figure 2. Schematic representation of the direction and significance of the dietinduced changes of gene expression during VLCD and during the entire DI in each depot is presented in Table 2.
Macrophage markers (Fig. 2A-2B)

The expression of 6 macrophage markers (CD68, ACP5, FCGBP, MSR1, PLA2G7, SPP1) increased during VLCD in both depots while expression of 3 remaining markers (CD14, TLR4, TLR2) was not changed in both depots. At the end of WM, the mRNA levels of all macrophage markers were not different from the baseline values in both depots (Fig. 2A-2B).

\section{Cytokines (Fig. 2C-2D)}

During VLCD, the mRNA levels of 5 cytokines (TNF, IL6, IL10RA, TGF $\beta 1$, CXCL1) did not change in either depot, CCL2 increased and CCR2 decreased in both depots and IL10 showed a significant increase 
Table 2. Changes of gene expression in subcutaneous abdominal (SAAT) and subcutaneous gluteal (sGAT) adipose tissue during VLCD and weight maintenance (WM) phases of dietary intervention in relation to the pre-diet (basal) level.

\begin{tabular}{|c|c|c|c|c|}
\hline \multirow{2}{*}{ Name of gene } & \multicolumn{2}{|c|}{ SAAT } & \multicolumn{2}{|c|}{ SGAT } \\
\hline & VLCD & WM & VLCD & WM \\
\hline \multicolumn{5}{|c|}{ Macrophage markers } \\
\hline CD68 & $* * \uparrow$ & $\leftrightarrow$ & $* \uparrow$ & $\leftrightarrow$ \\
\hline$A C P 5$ & $* * * \uparrow$ & $\leftrightarrow$ & $* * \uparrow$ & $\leftrightarrow$ \\
\hline$C D 14$ & $\leftrightarrow$ & $\leftrightarrow$ & $\leftrightarrow$ & $\leftrightarrow$ \\
\hline$F C G B P$ & $* * * \uparrow$ & $\leftrightarrow$ & $* * \uparrow$ & $\leftrightarrow$ \\
\hline MSR1 & $* * * \uparrow$ & $\leftrightarrow$ & $* * \uparrow$ & $\leftrightarrow$ \\
\hline PLA2G7 & $* * \uparrow$ & $\leftrightarrow$ & $* \uparrow$ & $\leftrightarrow$ \\
\hline$S P P 1$ & $* \uparrow$ & $\leftrightarrow$ & $* \uparrow$ & $\leftrightarrow$ \\
\hline TLR4 & $\leftrightarrow$ & $\leftrightarrow$ & $\leftrightarrow$ & $\leftrightarrow$ \\
\hline TLR2 & $\leftrightarrow$ & $\leftrightarrow$ & $\leftrightarrow$ & $\leftrightarrow$ \\
\hline
\end{tabular}

\section{Cytokines}

\begin{tabular}{lcccc}
\hline$T N F$ & $\leftrightarrow$ & $* \downarrow$ & $\leftrightarrow$ & $\leftrightarrow$ \\
$I L 10$ & $* \uparrow$ & $* \downarrow$ & $\leftrightarrow$ & $* \uparrow(\#)$ \\
$I L 6$ & $\leftrightarrow$ & $* \downarrow$ & $\leftrightarrow$ & $\leftrightarrow(\#)$ \\
$I L 10 R A$ & $\leftrightarrow$ & $* \downarrow$ & $* \uparrow$ & $\leftrightarrow$ \\
$C C L 2$ & $* \uparrow$ & $\leftrightarrow \downarrow$ & $* * \downarrow$ & $* \#)$ \\
$C C R 2$ & $* * \downarrow$ & $\leftrightarrow$ & $\leftrightarrow$ & $\leftrightarrow$ \\
$T G F \beta$ & $\leftrightarrow$ & $\leftrightarrow$ & $\leftrightarrow$ \\
$C X C L 1$ & $\leftrightarrow$ & $\leftrightarrow$ & $\leftrightarrow$ & $\leftrightarrow$ \\
\hline
\end{tabular}

$\uparrow$ denotes a higher level of gene expression at the end of respective dietary phase (VLCD or WM) in relation to the pre-diet (basal) level; $\downarrow$ denotes a lower level of gene expression in relation to the pre-diet (basal) level; $\leftrightarrow$ denotes no change in gene expression in relation to the pre-diet (basal) level; $*, * *, * * *$ denotes the level of significance $(p<0.05, p<0.01, p<0.001$, respectively) of the difference between the value at the end of respective dietary phase vs. pre-diet (basal) level; \#\# denotes the level of significance $(p<0.01)$ of the difference between sGAT and SAAT in respect to the change of gene expression during respective dietary phase (as assessed by two-way ANOVA)

selectively in SAAT.

At the end of DI, IL10 and CCL2 mRNA levels were higher than baseline values in SGAT while, in sAAT, the mRNA levels of these two cytokines as well as those of IL6, IL10RA and TNF were lower when compared with the baseline.

The diet-induced changes of mRNA levels were similar in the two depots for all of the cytokine genes with 3 exceptions: during the entire DI, expression of IL10, IL6, and CCL2 decreased in SAAT while it increased or was unaltered in sGAT.

Summary of the comparison of the diet-induced responses of the gene expression in SGAT and SAAT

For majority of measured genes no differences in the diet-induced changes between sGAT and sAAT were found. Different responses were found only for the
3 cytokines (IL10, IL6, CCL2): their decrease during the entire DI was pronounced in sAAT but not in sGAT.

\section{Correlations}

No correlations between the diet-induced changes of mRNA expression of examined genes in sGAT vs. SAAT were found. No correlations were found between the diet-induced changes of plasma levels of IL10, IL6, TNF, CCL2 and the changes in the expression of these genes in either sGAT or SAAT. In addition, no correlations between the diet-induced changes of mRNA expression of examined genes and those of BMI or HOMA-IR were found.

\section{Discussion}

It was hypothesized that the protective role of 
AT accumulation in the lower body, in respect to cardiovascular risk and metabolic disturbances, might be based on the lower pro-inflammatory profile of sGAT. However, recent work of Evans et al. (2011) reported that the expression of several pro-inflammatory markers was higher in sGAT compared to SAAT in a mixed group of lean and obese black and white South African women. Our work extended the range of explored genes and showed that, in a wide group of cytokines and macrophage markers, there were, with exception of 4 genes, no differences between sAAT and sGAT at baseline. Taken together, our and Evans' results do not support the hypothesis of the lower pro-inflammatory profile of sGAT. This is in line with the finding reported by Tchoukalova et al. (2010) that subcutaneous abdominal and femoral fat depot did not differ in number of macrophages in lean men and women.

The main interest of this study lies in the comparison of gene regulation in sAAT vs. SGAT in dynamic condition represented by two phases of a 6 months' dietary intervention. The pattern of the expression of macrophage markers observed in this study, including the increase during initial VLCD phase is in agreement with our previous work carried out in SAAT in another cohort of subjects (Capel et al. 2009). The pattern is bi-phasic, characterized by an increased expression during VLCD and a decrease towards baseline values during subsequent weight maintenance phase of the diet. Increased expression of macrophage markers during VLCD might be associated with enhanced fatty acids release from adipocytes as a possible trigger of macrophage activation and infiltration mediated by TLR 4 signaling as shown before (Kosteli et al. 2010, Suganami et al. 2005). Importantly, this bi-phasic response of macrophage markers expression was similar in sGAT when compared with sAAT (Fig. 2, Table 2) and the magnitudes of the diet-induced changes were not different in the two fat depots (Table 2). This finding suggests the same regulation of macrophage infiltration in sGAT and sAAT during weight-reducing dietary intervention.

The bi-phasic pattern of the diet-induced regulation was found also in the expression of cytokines derived predominantly from the cells of stromavascular fraction. This pattern was in accordance with previous results obtained in SAAT in a different cohort of subjects (Siklova-Vitkova et al. 2012). The magnitudes of the diet-induced changes were not different between sGAT and sAAT - except for three cytokines - IL6, IL10 and
CCL2. The observed variability in respect to the individual cytokine genes is, again, in agreement with the above mentioned study of Siklova-Vitkova et al. (2012): in that study the same three cytokine genes were the only ones that showed a significant decrease in sAAT at the end of dietary intervention. This partial differential depotrelated response - limited to the expression of the three cytokines - might be linked to differential response of endocannabinoid system as observed in the study of Bennetzen et al. (2011). In fact, during the weightreducing diet the authors found different change of expression of cannabinoid receptor type 1 in sGAT when compared with sAAT. And endocannabinoids were shown to inhibit production of several proinflammatory cytokines in primary human Muller cells (Krishnan and Chatterjee 2012). This mechanism could be taken into account, although no such regulation has been reported in adipose tissue. Moreover, in resting condition, Rantalainen et al. (2011) found differential expression of $12 \%$ of measured microRNA (e.g. miR146-5b, miR-21, miR155) in sGAT when compared with sAAT which could imply a differential expression of targets of these microRNA such as IL10 (Quinn and O'neill 2011) in the two fat depots.

The lack of correlations in gene expression changes between sAAT and sGAT suggests that, in spite of the similar pattern of the diet-induced response of the gene expression in the two fat depots, there is no direct quantitative association of the magnitude of the change between these two depots. In light of our and others results demonstrating the absence of major differences between sGAT and SAAT it has been suggested that the deleterious effect of upper body obesity could be mediated by the excess of visceral adipose tissue (VAT) and not excess of sAAT. Nevertheless, several studies showed that both, VAT and sAAT, are associated with the increased risk of metabolic profile and proinflammatory status (although the association was stronger with VAT) (Fox et al. 2007, Oka et al. 2010, Pou et al. 2007).

Furthermore, it should be noted that the present study compared sGAT and SAAT on transcriptional level. Due to the lack of sufficient amount of adipose tissue we did not explore the protein levels of cytokines in adipose tissues or their levels of secretion. It is not excluded that the underlying causes of different physiological impact of sGAT vs. SAAT may be at the level of translation or posttranslational regulations of cytokine production or release. 
It is to be noted that the results of this study are limited to women. Female adipose tissue shows different metabolic and endocrine characteristics (Kern et al. 2003, Montague et al. 1997) when compared with men. Moreover, the initial fat distribution in our set of women (mean $\mathrm{WHR}=0.861 \pm 0.0$ ) might play a role in the dietinduced response of the two fat depots although the reports on the effect of initial fat distribution on the body fat reduction are not unequivocal (Svendsen et al. 1995, Jones and Edwards 1999).

In conclusion, we did not find major differences in mRNA levels of macrophage markers and cytokines between SAAT and SGAT at baseline condition or in the pattern of their regulation in response to two phases of hypocaloric weight-reducing dietary intervention (with exception of 3 cytokines that were differentially regulated during weight maintenance phase). Therefore, our results do not bring evidence of an altered pro-inflammatory status or an altered "responsiveness" of immune cells in sGAT when compared with sAAT. Further research elucidating the molecular base of the protective role of sGAT fat depot is therefore warranted.

\section{Conflict of Interest}

There is no conflict of interest.

\section{Acknowledgements}

This work was supported by grant IGA NT 11450-3-2010 of the Ministry of Health, PRVOUK M-P31, Collaborative Project ADAPT (www.adapt-eu.net), Contract No. HEALTH-F2-2008-2011 00 and by GACR P 301/11/0748. We are indebted to Dr. Jan Polak for help with adipose tissue biopsies and Zuzana Parizkova for technical expertise.

\section{References}

ARNER P, LITHELL H, WAHRENBERG H, BRÖNNEGARD M: Expression of lipoprotein lipase in different human subcutaneous adipose tissue regions. J Lipid Res 32: 423-429, 1991.

BENNETZEN MF, WELLNER N, AHMED SS, AHMED SM, DIEP TA, HANSEN HS, RICHELSEN B, PEDERSEN SB: Investigations of the human endocannabinoid system in two subcutaneous adipose tissue depots in lean subjects and in obese subjects before and after weight loss. Int J Obes 35: 1377-1384, 2011.

BERMAN DM, NICKLAS BJ, ROGUS EM, DENNIS KE, GOLDBERG AP: Regional differences in adrenoceptor binding and fat cell lipolysis in obese, postmenopausal women. Metabolism 47: 467-473, 1998.

BERMAN DM, NICKLAS BJ, RYAN AS, ROGUS EM, DENNIS KE, GOLDBERG AP: Regulation of lipolysis and lipoprotein lipase after weight loss in obese, postmenopausal women. Obes Res 12: 32-39, 2004.

BJORNTORP P, CARLGREN G, ISAKSSON B, KROTKIEWSKI M, LARSSON B, SJOSTROM L: Effect of an energy-reduced dietary regimen in relation to adipose tissue cellularity in obese women. Am J Clin Nutr 28: 445-452, 1975.

CANOY D, BOEKHOLDT SM, WAREHAM N, LUBEN R, WELCH A, BINGHAM S, BUCHAN I, DAY N, KHAW K-T: Body fat distribution and risk of coronary heart disease in men and women in the European Prospective Investigation Into Cancer and Nutrition in Norfolk Cohort: a population-based prospective study. Circulation 116: 2933-2943, 2007.

CAPEL F, KLIMCAKOVA E, VIGUERIE N, ROUSSEL B, VITKOVA M, KOVACIKOVA M, POLAK J, KOVACOVA Z, GALITZKY J, MAORET JJ, HANACEK J, PERS TH, BOULOUMIE A, STICH V, LANGIN D: Macrophages and adipocytes in human obesity: adipose tissue gene expression and insulin sensitivity during calorie restriction and weight stabilization. Diabetes 58: 1558-1567, 2009.

EVANS J, GOEDECKE JH, SODERSTROM I, BUREN J, ALVEHUS M, BLOMQUIST C, JONSSON F, HAYES PM, ADAMS K, DAVE JA, LEVITT NS, LAMBERT EV, OLSSON T: Depot- and ethnic-specific differences in the relationship between adipose tissue inflammation and insulin sensitivity. Clin Endocrinol (Oxf) 74: 5159, 2011.

FALOIA E, TIRABASSI G, CANIBUS P, BOSCARO M: Protective effect of leg fat against cardiovascular risk factors in obese premenopausal women. Nutr Metab Cardiovasc Dis 19: 39-44, 2009.

FERRARA CM, LYNCH NA, NICKLAS BJ, RYAN AS, BERMAN DM: Differences in adipose tissue metabolism between postmenopausal and perimenopausal women. J Clin Endocrinol Metab 87: 4166-4170, 2002. 
FOLSOM AR, KAYE SA, SELLERS TA, HONG CP, CERHAN JR, POTTER JD, PRINEAS RJ: Body fat distribution and 5-year risk of death in older women. JAMA 269: 483-487, 1993.

FOX CS, MASSARO JM, HOFFMANN U, POU KM, MAUROVICH-HORVAT P, LIU C-Y, VASAN RS, MURABITO JM, MEIGS JB, CUPPLES LA, D'AGOSTINO RB Sr, O'DONNELL CJ: Abdominal visceral and subcutaneous adipose tissue compartments: association with metabolic risk factors in the Framingham Heart Study. Circulation 116: 39-48, 2007.

JONES PRM, EDWARDS DA: Areas of fat loss in overweight young females following an 8-week period of energy intake reduction. Ann Hum Biol 26: 151-162, 1999.

KERN PA, DI GREGORIO GB, LU T, RASSOULI N, RANGANATHAN G: Adiponectin expression from human adipose tissue: relation to obesity, insulin resistance, and tumor necrosis factor- $\alpha$ expression. Diabetes $\mathbf{5 2}$ : 1779-1785, 2003.

KLIMCAKOVA E, ROUSSEL B, KOVACOVA Z, KOVACIKOVA M, SIKLOVA-VITKOVA M, COMBES M, HEJNOVA J, DECAUNES P, MAORET J, VEDRAL T, VIGUERIE N, BOURLIER V, BOULOUMIÉ A, STICH V, LANGIN D: Macrophage gene expression is related to obesity and the metabolic syndrome in human subcutaneous fat as well as in visceral fat. Diabetologia 54: 876-887, 2011.

KOSTELI A, SUGARU E, HAEMMERLE G, MARTIN JF, LEI J, ZECHNER R, FERRANTE AW Jr: Weight loss and lipolysis promote a dynamic immune response in murine adipose tissue. $J$ Clin Invest 120: 3466-3479, 2010.

KRISHNAN G, CHATTERJEE N: Endocannabinoids alleviate proinflammatory conditions by modulating innate immune response in muller glia during inflammation. Glia 60: 1629-1645, 2012.

MAURIEGE P, IMBEAULT P, LANGIN D, LACAILLE M, ALMERAS N, TREMBLAY A, DESPRES JP: Regional and gender variations in adipose tissue lipolysis in response to weight loss. J Lipid Res 40: 1559-1571, 1999.

MONTAGUE CT, PRINS JB, SANDERS L, DIGBY JE, O'RAHILLY S: Depot- and sex-specific differences in human leptin mRNA expression: implications for the control of regional fat distribution. Diabetes 46: 342-347, 1997.

O'HARA A, LIM FL, MAZZATTI DJ, TRAYHURN P: Microarray analysis identifies matrix metalloproteinases (MMPs) as key genes whose expression is up-regulated in human adipocytes by macrophage-conditioned medium. Pflugers Arch 458: 1103-1114, 2009.

OKA R, MIURA K, SAKURAI M, NAKAMURA K, YAGI K, MIYAMOTO S, MORIUCHI T, MABUCHI H, KOIZUMI J, NOMURA H, TAKEDA Y, INAZU A, NOHARA A, KAWASHIRI M-A, NAGASAWA S, KOBAYASHI J, YAMAGISHI M: Impacts of visceral adipose tissue and subcutaneous adipose tissue on metabolic risk factors in middle-aged Japanese. Obesity 18: 153-160, 2010.

PISCHON T, BOEING H, HOFFMANN K, BERGMANN M, SCHULZE MB, OVERVAD K, VAN DER SCHOUW YT, SPENCER E, MOONS KGM, TJØNNELAND A, HALKJAER J, JENSEN MK, STEGGER J, CLAVELCHAPELON F, BOUTRON-RUAULT M-C, CHAJES V, LINSEISEN J, KAAKS R, TRICHOPOULOU A, TRICHOPOULOS D, BAMIA C, SIERI S, PALLI D, TUMINO R, VINEIS P, PANICO S, PEETERS PHM, MAY AM, BUENO-DE-MESQUITA HB, VAN DUIJNHOVEN FJB, HALLMANS G, WEINEHALL L, MANJER J, HEDBLAD B, LUND E, AGUDO A, ARRIOLA L, BARRICARTE A, NAVARRO C, MARTINEZ C, QUIRÓS JR, KEY T, BINGHAM S, KHAW KT, BOFFETTA P, JENAB M, FERRARI P, RIBOLI E: General and abdominal adiposity and risk of death in Europe. New Engl J Med 359: 2105-2120, 2008.

POU KM, MASSARO JM, HOFFMANN U, VASAN RS, MAUROVICH-HORVAT P, LARSON MG, KEANEY JF, MEIGS JB, LIPINSKA I, KATHIRESAN S, MURABITO JM, O’DONNELL CJ, BENJAMIN EJ, FOX CS: Visceral and subcutaneous adipose tissue volumes are cross-sectionally related to markers of inflammation and oxidative stress: the Framingham Heart Study. Circulation 116: 1234-1241, 2007.

QUINN SR, O'NEILL LA: A trio of microRNAs that control Toll-like receptor signalling. Int Immunol 23: 421-425, 2011.

RANTALAINEN M, HERRERA BM, NICHOLSON G, BOWDEN R, WILLS QF, MIN JL, NEVILLE MJ, BARRETT A, ALLEN M, RAYNER NW, FLECKNER J, MCCARTHY MI, ZONDERVAN KT, KARPE F, HOLMES CC, LINDGREN CM: MicroRNA expression in abdominal and gluteal adipose tissue is associated with mRNA expression levels and partly genetically driven. PLOS ONE 6: e27338, 2011. 
RUIGE JB, VAN GAAL LF: Low fasting triglycerides: hallmark of the healthy large hip? Obesity 17: 1621-1626, 2009.

SEIDELL JC, PÉRUSSE L, DESPRÉS J-P, BOUCHARD C: Waist and hip circumferences have independent and opposite effects on cardiovascular disease risk factors: the Quebec Family Study. Am J Clin Nutr 74: 315-321, 2001.

SIKLOVA-VITKOVA M, KLIMCAKOVA E, POLAK J, KOVACOVA Z, TENCEROVA M, ROSSMEISLOVA L, BAJZOVA M, LANGIN D, STICH V: Adipose tissue secretion and expression of adipocyte-produced and stromavascular fraction-produced adipokines vary during multiple phases of weight-reducing dietary intervention in obese women. J Clin Endocrinol Metab 97: E1176-E1181, 2012.

SNIJDER MB, ZIMMET PZ, VISSER M, DEKKER JM, SEIDELL JC, SHAW JE: Independent and opposite associations of waist and hip circumferences with diabetes, hypertension and dyslipidemia: the AusDiab Study. Int J Obes Relat Metab Disord 28: 402-409, 2004.

SUGANAMI T, OGAWA Y: Adipose tissue macrophages: their role in adipose tissue remodeling. $J$ Leukoc Biol 88: 33-39, 2010.

SUGANAMI T, NISHIDA J, OGAWA Y: A paracrine loop between adipocytes and macrophages aggravates inflammatory changes: role of free fatty acids and tumor necrosis factor $\alpha$. Arterioscler Thromb Vasc Biol 25: 2062-2068, 2005.

SVENDSEN O, HASSAGER C, CHRISTIANSEN C: Age- and menopause-associated variations in body composition and fat distribution in healthy women as measured by dual-energy X-ray absorptiometry. Metabolism 44: 369373, 1995.

TCHOUKALOVA YD, KOUTSARI C, VOTRUBA SB, TCHKONIA T, GIORGADZE N, THOMOU T, KIRKLAND JL, JENSEN MD: Sex- and depot-dependent differences in adipogenesis in normal-weight humans. Obesity 18: 1875-1880, 2010.

TRAYHURN P, WOOD IS: Adipokines: inflammation and the pleiotropic role of white adipose tissue. Br J Nutr 92: 347-355, 2004. 